\title{
Evaluation of the impact on quality of life of patients with temporomandibular disorders*
}

\author{
Avaliação do impacto na qualidade de vida de pacientes com disfunção temporomandibular
}

Carolina Almeida Rodrigues ${ }^{1}$, Lais Valencise Magri ${ }^{1}$, Melissa de Oliveira Melchior ${ }^{1}$, Marcelo Oliveira Mazzetto ${ }^{1}$

${ }^{*}$ Received from the School of Dentistry of Ribeirão Preto, Ribeirão Preto, SP, Brazil.

DOI 10.5935/1806-0013.20150036

\section{ABSTRACT}

BACKGROUND AND OBJECTIVES: Chronic pain, such as temporomandibular disorder, often leads to significant changes in quality of life. This study aimed at evaluating the influence of temporomandibular disorders in the subjective perception of quality of life by means of the Oral Health Impact Profile-14.

METHODS:Participated in the study 80 patients diagnosed with temporomandibular disorders by means of the Research Diagnostic Criteria for Temporomandibular Disorders, aged between 18 and 60 years $(32.71 \pm 1.1)$, who were submitted to the Oral Health Impact Profile-14 questionnaire. Non parametric Mann-Whitney statistics, Pearson Correlation test, Analysis of Variance and Tukey test were used with significance level of 5\%. RESULTS: There has been no statistically significant difference in the perception of the impact on quality of life between genders; patients with association of signs and symptoms of the three groups of the Research Diagnostic Criteria for Temporomandibular Disorders had further impact on quality of life, as well as the most severe the temporomandibular disorder the highest the reported impact $(\mathrm{p}=0.05)$, and the age group with the highest impact on quality of life was between 18 and 30 years $(\mathrm{p}<0.01)$.

CONCLUSION: Increased age, severity and the association of diagnoses have exacerbated the impact of temporomandibular disorders on quality of life. Variables analyzed in this study were related to temporomandibular disorder chronicity, stressing the importance of early intervention strategies to minimize the impact on quality of life.

Keywords: Chronic pain, Quality of life, Temporomandibular joint disorder syndrome.

1. Faculdade de Odontologia de Ribeirão Preto, Ribeirão Preto, SP, Brasil.

Submitted in February 26, 2015

Accepted for publication in July 27, 2015.

Conflict of interests: none - Sponsoring sources: CAPES.

Correspondence to:

Carolina Almeida Rodrigues

Rua Benjamin Anderson Stauffer, 901 - Jardim Botânico

14021-617 Ribeirão Preto, SP, Brasil.

E-mail: carolinaalmeidarodrigues@hotmail.com

(C) Sociedade Brasileira para o Estudo da Dor

\section{RESUMO}

JUSTIFICATIVA E OBJETIVOS: Dores crônicas, como as disfunçôes temporomandibulares, levam com frequência a alteraçóes significativas na qualidade de vida. $\mathrm{O}$ objetivo deste estudo foi avaliar a influência da disfunção temporomandibular na percepção subjetiva da qualidade de vida, obtida por meio do Oral Health Impact Profile-14.

MÉTODOS: Oitenta pacientes diagnosticados com disfunção temporomandibular por meio dos critérios do ResearchDiagnosticCriteria for Temporomandibular Disorders, com idade entre 18 e 60 anos $(32,71 \pm 11,1)$, foram submetidos ao questionário Oral Health Impact Profile-14. Empregaram-se a estatística não paramétrica de Mann-Whitney, teste de Correlação de Pearson e Análise de Variância e teste de Tukey, adotando-se 5\% como nível de significância.

RESULTADOS: Não houve diferença estatisticamente significativa quanto à percepção do impacto na qualidade de vida entre os gêneros; pacientes com associação de sinais e sintomas dos três grupos do Research Diagnostic Criteria for Temporomandibular Disorders apresentaram maior impacto na qualidade de vida,assim como, quanto maior a gravidade da disfunção temporomandibular maior é o impacto relatado $(p=0,05)$ e a faixa etária com maior impacto na qualidade de vida encontrava-se entre 18 e 30 anos $(\mathrm{p}<0,01)$.

CONCLUSÃO: O aumento da idade, a gravidade e a associação de diagnósticos exacerbaram o impacto da disfunção temporomandibular na qualidade de vida. As variáveis analisadas neste estudo relacionam-se com a cronicidade da disfunção temporomandibular, ressaltando a importância de estratégias de intervenção precoce para minimizar o comprometimento da qualidade de vida.

Descritores: Dor crônica, Qualidade de vida, Síndrome da disfunção da articulação temporomandibular.

\section{INTRODUCTION}

Temporomandibular disorders (TMD) are a significant public health problem, affecting significant part of the population. TMD is more predominant in individuals between 20 and 40 years of age ${ }^{1}$ and in females ${ }^{2,3}$.

Pain is the most common complaint of TMD patients and sometimes the primary reason for looking for treatment ${ }^{4}$. Pain may affect face, head, neck and ears, and joint noises during 
mouth opening and/or closing, decreased jaw movement amplitude, ear plugging, eye pain and tearing, difficulty to speak and swallow may also be present ${ }^{2,5,6}$.

TMDs have several risk factors, including macro and microtraumas, skeletal or occlusal changes, systemic factors, masticatory and/or cervical muscles hyperactivity, changes in temporomandibular joint (TMJ) collagen matrix, hormonal and genetic factors. In addition, psychological factors may contribute for the etiology of the disorder, particularly physical symptoms which may be associated or not to painful symptoms and which may be followed by emotional stress situations resulting in increased excitability of head and neck muscles. Depression, for example, is especially observed in young patients with masticatory function limitation associated to intra-joint disorders, especially osteoarthritis ${ }^{7}$.

Quality of life (QL) is related to individuals' subjective perception of their position in life, in the context of values and culture in which they live, and with regard to their objectives, expectations and concerns. Patients with chronic pain, including TMD, often have significant QL changes ${ }^{8,9}$. This is highly clinically important as daily life activities of such patients, involving basic functions such as chewing, speaking, swallowing and even social activities, may be impaired by pain and/or movement limitations, making the investigation of the level of QL impairment paramount for pain area professionals.

The association of clinical TMD presentations and minor psychiatric disorders, such as anxiety, depression and stress, has also been extensively reported by the literature. There is also major relationship among pain scores, QL and psychological aspects since the more severe are TMD and pain, the more impaired are the described items ${ }^{10}$. So, the assistance of TMD patients demands a clinical approach aimed at different aspects, among them QL, because it represents the subjective perception of patients.

TMD subclinical type, depending on muscle and/or joint involvement, as well as chronicity and pain catastrophizing process, are also variables directly influencing the impact on QL. The proposition of therapies aiming at promoting some degree of analgesia and at bringing more comfort to patients, such as stabilizing occlusal splints, may change QL perception and modulate psychological aspects related to clinical manifestations of TMD signs and symptoms ${ }^{10-12}$.

Many times, patients' perception and feelings with regard to their oral health are ignored, however it is notorious the importance of evaluating the impact on individuals suffering from chronic pain, and the use of tools to evaluate TMD impact on QL of affected patients is critical to establish the need for treatment and to evaluate the success of applied therapies ${ }^{8}$. This study aimed at evaluating the influence of TMD on subjective QL perception, obtained by means of the Oral Health Impact Profile-14 (OHIP-14).

\section{METHODS}

This is an observational, descriptive and cross-sectional study. Participated in the study 80 patients (70 females and 10 males) aged between 18 and 60 years (mean age $32.71 \pm 11.1$ years) with TMD signs and symptoms. Inclusion criteria were orofacial pain for at least six months and TMD diagnosis established by the Research Diagnostic Criteria for Temporomandibular Disorders (RDC/TMD) ${ }^{13}$. Exclusion criteria were patients with history of facial trauma, tumors and/or major surgeries, neurological and/or psychiatric diseases with cognitive impairment, patients under continuous use of antidepressants, anxiolytics and/or anticonvulsants and pregnant women.

RDC/TMD has provided TMD diagnosis based on clinical criteria, as well as classification according to groups: muscle disorders (group 1), disc displacement disorders (group 2), arthralgia and osteoarthritis (group 3). Craniomandibular Index $(\mathrm{CMI})^{14}$ was used to standardize disorder severity, considering Disorder Index (DI) and Palpation Index (PI). CMI was calculated by adding DI and PI and dividing by two, with results varying from zero to 1 , both applied by a single, previously trained investigator. Severity was classified based on the following reasoning: CMI scores vary from zero to 1 . Maximum value was divided by three (related to mild, moderate and severe), obtaining a value of 0.33 . So, zero to 0.33 was considered mild TMD, 0.34 to 0.67 moderate and 0.68 to 1 severe TMD.

The impact on QL was evaluated by the OHIP-14 tool reduced to 14 questions ${ }^{15}$ and validated to the Portuguese langua$\mathrm{ge}^{16}$. The tool was applied as an interview and has evaluated factors which may or may not be associated to the impact of TMDs: functional limitation, physical pain, psychological distress, physical limitation, psychological limitation, social limitation and incapacity. Two questions were asked to evaluate each analyzed factor and for each of them patients had the option of answering about the frequency it would occur. Answers could be: always, frequently, sometimes, seldom, never, or did not know/had not noticed the occurrence of what had been asked.

Each answer received a score which was multiplied by the specific weight of each question. This way, when adding final score, values obtained were between zero and 28 points. The highest the score, the highest the perception of impact on QL.

Data distribution was checked by means of D'Agostino Pearson test, considering $\mathrm{p} \geq 0.05$ the normality of the sample. Variables: OHIP-14 scores, CMI and age had normal distribution and parametric statistics was used: Pearson Correlation test to evaluate the level of association between OHIP-14 and CMI and Analysis of Variance (1 criterion) to understand variations of OHIP-14 scores as a function of age. Gender variable had not normal distribution, so Mann-Whitney test was used to evaluate QL impact variation as a function of gender. It is relevant to stress that for all described tests, adopted decision level was 5\% ( $\leq 0.05)$. Only descriptive statistics was used for RDC/TMD data.

This study was approved by the Research Ethics Committee, School of Dentistry of Ribeirão Preto - USP (0041.0.138.0002011). 


\section{RESULTS}

Within selected sample, according to inclusion and exclusion criteria, there has been higher prevalence of females (70 females and 10 males) with mean age of $32.71 \pm 11.1$ years. Clinical evaluations by RDC/TMD have established diagnostic classification of the sample: $1 \%$ group I; $44 \%$ groups I and II; $15 \%$ groups I and III; $30 \%$ groups II and III; $10 \%$ groups I, II and III, showing higher prevalence of patients with the association of muscle and intra-articular signs and symptoms. With regard to OHIP-14 scores for each TDC/TMD diagnostic category, associations between groups had higher values as compared to isolated groups, indicating a higher impact on QL (Figure 1). The association of the three groups (I, II and III) had the highest score, with mean and standard deviation of $12.83 \pm 4.3$, followed by the association between I and II $(11.79 \pm 5.3)$, association between I and III $(10.78 \pm 5.1)$, association between II and III (8.7 \pm 6.51$)$, and group I (7.56). The severity of clinical TMD manifestation was measured by $\mathrm{CI}$, mean and standard deviation obtained for total sample was $0.52 \pm 0.1$, indicating moderate severity. Patients with severe TMD had higher mean value for QL impact $(13.41 \pm 5.14)$ as compared to patients with mild $(11.07 \pm 6.02)$ and moderate $(9.45 \pm 5.43)$ TMD. There has been significant correlation between CMI and OHIP-14 score ( $\mathrm{p}=0.05, \mathrm{r}=0.91$ - Pearson Correlation) (Table 1), showing higher impact on QL according to higher TMD severity.

With regard to gender, males had mean OHIP-14 score of $10.19 \pm 4.7$ and females, $10.71 \pm 5.7$, without statistically significant difference between groups $(\mathrm{p}=0.74)$. In OHIP-14 scores obtained according to age groups, there has been statistically significant difference for the group between 18 and 30 years of age as compared to the group between 31 and 45 years of age $(\mathrm{p}<0.01)$. There has been no difference when comparing both above-described age groups to the group between 46 and 60 years of age (Table 1) showing less impact on

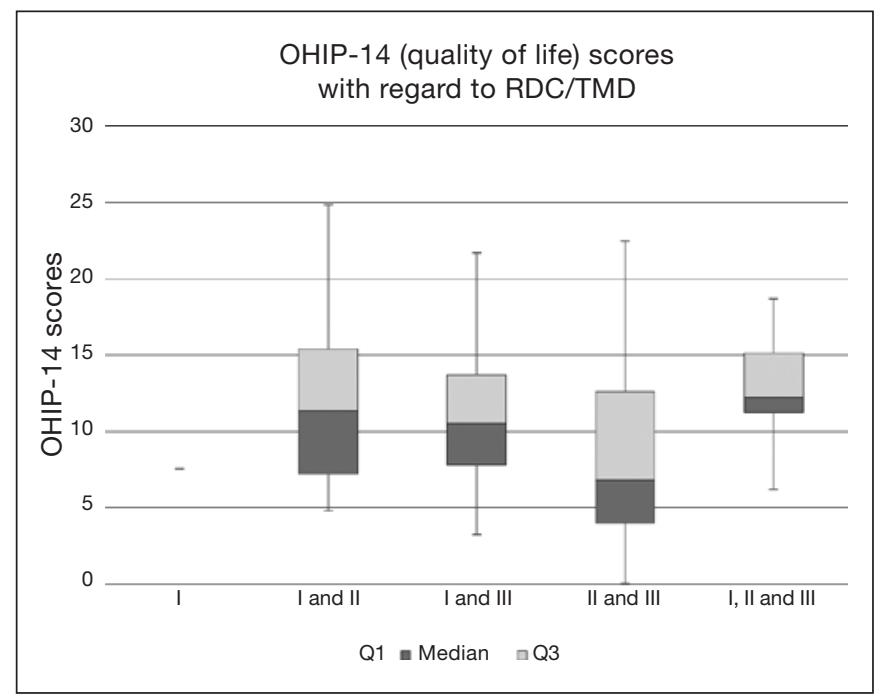

Figure 1. Relationship between Oral Health Impact Profile-14 scores and diagnosis obtained by means of the Research Diagnostic Criteria for Temporomandibular disorders
Table 1. Mean (standard deviation) of Oral Health Impact Profile-14 scores according to Craniomandibular Index, gender and age groups

\begin{tabular}{lccc}
\hline & $\begin{array}{c}\text { OHIP-14 mean (standard } \\
\text { deviation) }\end{array}$ & p value \\
\hline $\begin{array}{l}\text { Craniomandi- } \\
\text { bular index }\end{array}$ & OHIP - total & $10.64 \pm 5.6$ & $0.05(\mathrm{r}=0.91)^{\star}$ \\
Gender & ICM & $0.52 \pm 0.1$ & \\
& Male & $10.19 \pm 4.7$ & $0.74^{\star *}$ \\
Age group & Female & $10.71 \pm 5.7$ & \\
(years) & 18 to 30 & $8.81 \pm 4.4$ & Means $(1$ to 2$)=<0.01$ \\
& 31 to 45 & $13.4 \pm 6.3$ & Means $(1$ to 3$)=\mathrm{ss}^{* \star *}$ \\
& 46 to 60 & $10.8 \pm 5.3$ & \\
\hline
\end{tabular}

*Pearson Correlation Test; ${ }^{\star \star}$ Mann-Whitney Test; ${ }^{* \star \star}$ ANOVA - Tukey Test; ss: without significant statistics. Adopting $5 \%$ as significance level.

OHIP-14 = Oral Health Impact Profile-14; CMI = Craniomandibular Index.

QL of younger TMD patients (18 to 30 years).

Among aspects addressed by OHIP-14, "physical pain" was most often reported by the sample (76 have answered positively to questions 3 and 4), followed by "psychological distress" (71 to question 5 and 65 to question 6) and by "psychological limitation (56 to question 9 and 30 to question 10) (Table 2).

Table 2. Number of patients answering positively to specific Oral Health Impact Profile-14 questions, according to general items (functional limitation, physical pain, psychological distress, physical limitation, psychological limitation, social limitation and incapacity) $(n=80)$

\begin{tabular}{llc}
\hline $\begin{array}{l}\text { OHIP-14 ite- } \\
\mathrm{ms}\end{array}$ & $\begin{array}{l}\text { Specific questions for each } \\
\text { item }\end{array}$ & $\begin{array}{c}\text { Number of pa- } \\
\text { tients with positive } \\
\text { answers } \\
(\mathrm{n}=80)\end{array}$ \\
\hline
\end{tabular}

Functional 1. Have you had problems limitation saying a word due to problems with your mouth or joint?

29

2. Have you felt that food taste has worsened due to problems with your mouth or joint?

Physical 3. Have you felt pain in your pain mouth or joint?

4. Were you discomfort when eating some food due to problems with your mouth or joint?

Psychologi- 5. Were you concerned due cal distress to problems with your mouth or joint?

6. Were you stressed due to problems with your mouth or joint?

Physical li- 7. Was your diet impaired mitation due to problems with your mouth or joint?

8. Have you had to stop your meals due to problems with your mouth or joint?

\section{6}

76

71

65

45

39

Continues... 
Table 2. Number of patients answering positively to specific Oral Health Impact Profile-14 questions, according to general items (functional limitation, physical pain, psychological distress, physical limitation, psychological limitation, social limitation and incapacity) $(n=80)$ - continuation

\begin{tabular}{|c|c|c|}
\hline $\begin{array}{l}\text { OHIP-14 ite- } \\
\mathrm{ms}\end{array}$ & $\begin{array}{l}\text { Specific questions for each } \\
\text { item }\end{array}$ & $\begin{array}{l}\text { Number of pa- } \\
\text { tients with positive } \\
\text { answers } \\
(n=80)\end{array}$ \\
\hline \multirow[t]{2}{*}{$\begin{array}{l}\text { Psychologi- } \\
\text { cal limitation }\end{array}$} & $\begin{array}{l}\text { 9. Was it difficult for you to } \\
\text { relax due to problems with } \\
\text { your mouth or joint? }\end{array}$ & 56 \\
\hline & $\begin{array}{l}\text { 10. Were you ashamed due } \\
\text { to problems with your mouth } \\
\text { or joint? }\end{array}$ & 30 \\
\hline \multirow[t]{2}{*}{$\begin{array}{l}\text { Social limi- } \\
\text { tation }\end{array}$} & $\begin{array}{l}\text { 11. Were you annoyed with } \\
\text { other people due to prob- } \\
\text { lems with your mouth or } \\
\text { joint? }\end{array}$ & 31 \\
\hline & $\begin{array}{l}\text { 12. Was it difficult for you to } \\
\text { perform daily activities due } \\
\text { to problems with your mouth } \\
\text { or joint? }\end{array}$ & 35 \\
\hline \multirow[t]{2}{*}{ Incapacity } & $\begin{array}{l}\text { 13. Have you felt that your } \\
\text { life in general has worsened } \\
\text { due to problems with your } \\
\text { mouth or joint? }\end{array}$ & 44 \\
\hline & $\begin{array}{l}\text { 14. Were you completely } \\
\text { unable to perform daily ac- } \\
\text { tivities due to problems with } \\
\text { your mouth or joint? }\end{array}$ & 17 \\
\hline
\end{tabular}

OHIP14 = Oral Health Impact Profile.

\section{DISCUSSION}

The perception of TMD impact on QL is important for the clinical handling of this condition, as well as for the therapeutic decision ${ }^{17}$. It is necessary to understand what TMD represents for those subjects and to what extent it modifies their lives, to guide diagnosis and intervention, because it is necessary to take care of what really annoys them and, as a consequence, makes their QL worse. In this sense, tools like OHIP may be important aids for the routine of TMD outpatient settings.

$\mathrm{OHIP}^{18}$ is a comprehensive and potentially adequate tool to evaluate impact on QL of TMD patients ${ }^{19}$ because it is divided into sessions which evaluate functional limitation, physical pain, psychological distress, physical limitation, psychological limitation, social limitation and incapacity. The tool, made up of 49 questions (OHIP-49) which describe the consequences of oral disorders, was considered valid and reliable for the detailed measurement of oral disorders social impact and with potential benefits for clinical and scientific research decision-making ${ }^{18}$. From this, a subset of OHIP-49 items was proposed, made up of 14 questions which still evaluate the perception of oral conditions impact on patients' wellbeing, to make easier and minimize the time to apply the tool. OHIP-14 has shown good reliability, validity and accuracy ${ }^{15}$.

van der Meulen et al. ${ }^{20}$ have evaluated psychometric characteris- tics of three OHIP versions which are used for clinical evaluation of TMD patients: OHIP-14, OHIP-NL14 and OHIP-NL5; all reduced versions of the OHIP questionnaire. Authors have concluded that OHIP-14 and OHIP-NL14 were better than OHIP-NL5 and that considering application time, OHIP-14 should be the preferred version because it takes a shorter time.

Several factors may worsen TMD, being one of them chronicity. Blanco-Aguilera et al. ${ }^{7}$ have carried out a study where they have also observed a direct relationship between clinical condition chronicity (considered by the study as 1 year or longer) and OHIP-14 score, being that the more chronic the condition, the higher the score, indicating worse QL. Another aspect evaluated by the authors was the difference in oral health perception between males and females, where females have more negatively perceived the oral health aspect, differently from our study and other studies found in the literature ${ }^{8}$.

Barros et al. ${ }^{8}$ have carried out a study similar to our study where they have evaluated relationships of gender, diagnosis and severity of TMD with self-report of QL. Authors have observed that orofacial pain has a huge impact on QL, however without differences between genders. The association of diagnoses between groups I and II has shown higher OHIP-14 scores. With regard to severity, there has been directly proportional relationship with QL. With regard to the lack of significant difference between genders in our study, a possible explanation could be the high prevalence of females with regard to the small number of males ${ }^{21}$.

With regard to advanced age and clinical diagnosis, Rener-Sitaret et al. ${ }^{22}$ have correlated several important variables of clinical TMD manifestation with perceived QL (OHIP-14) and have found that increased age, the association of diagnosis by RDC/ TMD and the presence of $\mathrm{lb}$ diagnosis were preponderant to explain $39.1 \%$ variability $(\mathrm{p}<0.001)$ of OHIP-14 scores. These results confirm the findings of our study, because there has been statistically significant difference for the group between 18 and 30 years of age as compared to remaining groups (31 to 45 and 46 to 60 years), with $\mathrm{p}<0.01$ showing worsening of $\mathrm{QL}$ with TMD and advanced age.

The association of RDC/TDM diagnoses was also a determinant variable for the perception of worse QL. Dahlström \& Carlsson $^{23}$ have carried out a review where they evaluated 12 studies which have shown substantial impact on QL of TMD patients, being that the difference between males and females was small and insignificant. The impact was more pronounced on patients with signs and symptoms and two studies have shown increased impact with increased age.

It is apparent that QL is directly influenced by chronicity of the disease. The determining factor of the transition of acute to chronic diseases is still controversial, but it is known that a very important predisposing factor is central sensitization. This is due to peripheral and central neuronal changes due to changes in nociceptive impulses demand, which may be in high magnitude or be repetitive, leading to pain maintenance and exacerbation $^{24}$

To understand patients with chronic pain, such as TMD, it is necessary to evaluate all existing biological, psychological and 
social aspects. In addition to the disease itself, it is known that such patients often present with hyperalgesia, allodynia and receptive field expansion, which may result in psycho-behavioral changes such as depression, high levels of anxiety and pain catastrophizing ${ }^{12}$ which are strongly associated to pain intensity and permanence, changing psychosocial behavior and QL of the individual. Miettinen, Lahti \& Sipilä ${ }^{25}$ emphasize the importance of using Axis II of RDC/TDM to evaluate QL of patients with TDM, in association with the OHIP-14 questionnaire. Phenomena such as depression and somatization may directly influence perceived QL and are frequent comorbidities of TMDs. This might have been a limitation of our study, because the incorporation and use of Axis II could have brought additional results and help further understanding of QL perception of TMD patients.

With regard to the frequency of positive answers to OHIP14 obtained for the studied sample, most reported items were "physical pain" and "psychological distress", showing the importance of painful symptoms and psychological comorbidities for the level of distress of such patients. It is important to note that "functional limitation" and "incapacity" were not frequently reported by this population, showing that they are not the primary reason for the perception of worse QL related to TMD. Functional limitations generated by TMD do not seem to affect perceived QL of such patients.

\section{CONCLUSION}

Increased age, severity and association of diagnoses exacerbate the impact of TMD on QL. Described variables are related to chronicity of this condition and for such it is necessary to develop early intervention strategies to prevent further QL impairment. We suggest the incorporation of the OHIP-14 questionnaire to TMD patients evaluation protocol aiming at enhancing the view of what is really representative and deman$\mathrm{d}$ s intervention.

\section{ACKNOWLEDMENTS}

We acknowledge the Coordination of Higher Education Personnel Improvement (CAPES) for their financial support.

\section{REFERENCES}

1. Zakrzewska JM. Differential diagnosis of facial pain and guidelines for management. Br J Anaesth. 2013;111(1):95-104.

2. Bagis B, Ayaz EA, Turgut S, Durkan R, Özcan M. Gender difference in prevalence of signs and symptoms of temporomandibular joint disorders: a retrospective study on 243 consecutive patients. Int J Med Sci. 2012;9(7):539-44.

3. Adèrn B, Stenvinkel C, Sahlgvist L, Tegelberg A. Prevalence of temporomandibular dysfunction and pain in adult general practice patients. Acta Odontol Scand. 2014;72(8):585-90.

4. Tjakkes GH, Reinders JJ, Tenvergert EM, Stegenga B. TMD pain: the effect on health related quality of life and the influence of pain duration. Health Qual Life Outcomes. 2010;8:46.

5. Mello CE, Oliveira JL, Jesus AC, Maia ML, de Santana JC, Andrade LS, et al. Term poromandibular disorders dysfunction in headache patients. Med Oral Patol Oral Cir Bucal. 2012;17(6)e1042-6.

6. Shaffer SM, Brismée JM, Sizer PS, Courtney CA. Temporomandibular disorders. Part 1: anatomy and examination/diagnosis. J Man Manip Ther. 2014;22(1):2-12.

7. Blanco-Aguilera A, Blanco-Hungría A, Biedma-Velázquez L, Serrano-Del-Rosal R, González-López L, Blanco-Aguilera E, et al. Application of an oral health-related quality of life questionnaire in primary care patients with orofacial pain and temporomandibular disorders. Med Oral Patol Oral Cir Bucal. 2014;19(2):e127-35.

8. Barros Vde M, Seraidarian PI, Côrtes MI, de Paula LV. The impact of orofacial pain on the quality of life of patients with temporomandibular disorder. J Orofac Pain. 2009;23(1):28-37.

9. Karacayli U, Mumcu G, Cimilli H, Sisman N, Sur H, Gunaydin Y. The effects of chronic pain on oral health related quality of life in patients with anterior disc displacement with reduction. Community Dent Health. 2011;28(3):211-5.

10. Resende CM, Alves AC, Coelho LT, Alchieri JC, Roncalli AG, Barbosa GA. Quality of life and general health in patients with temporomandibular disorders. Braz Oral Res. 2013;27(2):116-21.

11. Alajbeg IZ, Gikić M, Valentić-Peruzović M. Changes in pain intensity and oral health -related quality of life in patients with temporomandibular disorders during stabilization splint therapy--a pilot study. Acta Clin Croat. 2014;53(1):7-16.

12. Costa YM, Porporatti AL, Stuginski-Barbosa J, Bonjardim LR, Conti PC. Additional effect of occlusal splints on the improvement of psychological aspects in temporomandibular disorder subjects: a randomized controlled trial. Arch Oral Biol. 2015;60(5):738-44

13. Dworkin SF, LeResche L. Research diagnostic criteria for temporomandibular disorders: review, criteria, examinations and specifications, critique. J Craniomandib Disord. 1992;6(4):301-55.

14. Fricton JR, Schiffman EL. Reliability of a craniomandibular index. J Dent Res. 1986;65(11):1359-64.

15. Slade GD. Derivation and validation of a short-form oral health impact profile. Community Dent Oral Epidemiol. 1997;25(4):284-90.

16. Oliveira BH, Nadanovsky P. Psychometric properties of the Brazilian version of the Oral Health Impact Profile-short form. Community Dent Oral Epidemiol. 2005;33(4):307-14.

17. Schierz O, John MT, Reissmann DR, Mehrstedt M, Szentpétery A. Comparison of perceived oral health in patients with temporomandibular disorders and dental anxiety using oral health-related quality of life profiles. Qual Life Res. 2008;17(6):857-66.

18. Slade GD, Spencer AJ. Development and evaluation of the Oral Health Impact Profile. Community Dent Health. 1994;11(1):3-11.

19. John MT, Reissmann DR, Schierz O, Wassell RW. Oral health-related quality of life in patients with temporomandibular disorders. J Orofac Pain. 2007;21(1):46-54

20. van der Meulen MJ, John MT, Naeije M, Lobbezoo F. Developing abbreviated OHIP versions for use with TMD patients. J Oral Rehabil. 2012;39(1):18-27.

21. Rusanen J, Silvola AS, Tolvanen M, Pirttiniemi P, Lahti S, Sipilä K. Pathways between temporomandibular disorders, occlusal characteristics, facial pain, and oral health-related quality of life among patients with severe malocclusion. Eur J Orthod. 2012;34(4):512-7.

22. Rener-Sitar K, Celebić A, Mehulić K, Petricević N. Factors related to oral health related quality of life in TMD patients. Coll Antropol. 2013;37(2):407-13.

23. Dahlström L, Carlsson GE. Temporomandibular disorders and oral health-related quality of life. A systematic review. Acta Odontol Scand. 2010;68(2):80-5.

24. Conti PC, Pinto-Fiamengui LM, Cunha CO, Conti AC. Orofacial pain and temporomandibular disorders - the impact on oral health and quality of life. Braz Oral Res. 2012;26(Suppl 1):120-3.

25. Miettinen O, Lahti S, Sipilä K. Psychosocial aspects of temporomandibular disorders and oral health-related quality-of-life. Acta Odontol Scand. 2012;70(4):331-6. 